$31(1) \mid 2002$

Varia

\title{
“¡Huayra huayra pichcamanta!": Augurio, risa y regeneración en la política tradicional (Pacota, Huarochirí)
}

"¡Huayra huayra pichcamanta!" : augure, rires et régénération dans la politique traditionnelle (Pacota, Huarochirí)

"¡Huayra huayra pichcamanta!": Augury, Laughter, and Regeneration in an Andean Political Regime (Pacota, Huarochirí)

\section{Frank Salomon}

\section{(2) OpenEdition}

\section{Journals}

Edición electrónica

URL: http://journals.openedition.org/bifea/6900

DOI: $10.4000 /$ bifea.6900

ISSN: 2076-5827

Editor

Institut Français d'Études Andines

Edición impresa

Fecha de publicación: 1 abril 2002

Paginación: 1-22

ISSN: 0303-7495

Referencia electrónica

Frank Salomon, " "Huayra huayra pichcamanta!": Augurio, risa y regeneración en la política tradicional (Pacota, Huarochirí) », Bulletin de l'Institut français d'études andines [En línea], 31 (1) | 2002, Publicado el 08 abril 2002, consultado el 07 diciembre 2020. URL : http://journals.openedition.org/bifea/6900 ; DOl : https://doi.org/10.4000/bifea.6900

\section{(c) (†) $\ominus$}

Les contenus du Bulletin de l'Institut français d'études andines sont mis à disposition selon les termes de la licence Creative Commons Attribution - Pas d'Utilisation Commerciale - Pas de Modification 4.0 International. 


\title{
“¡HUAYRA HUAYRA PICHCAMANTA!”: AUGURIO, RISA Y REGENERACIÓN EN LA POLÍTICA TRADICIONAL (PACOTA, HUAROCHIRÍ) *
}

\author{
Frank SALOMON ${ }^{* *}$
}

\section{Resumen}

Una variante del juego-oráculo de la pichca, diferente de las versiones estudiadas por Gentile Lafaille (1998), facilita el augurio anual para el agropastoralismo en el centro de la provincia de Huarochirí (departamento de Lima, Perú). La nota lúdica predomina, pero las prácticas y creencias en torno al juego también traen consecuencias prácticas. En la actualidad, como en el manuscrito quechua de Huarochirí de 1608 [?], el padrón llamado dualismo alternante sirve para regenerar el orden político frente a los imponderables del clima y de la historia.

Palabras claves: Etnografía, etnohistoria, religión, ritos, juegos, Huarochirí.

\section{“¡HUAYRA HUAYRA PICHCAMANTA!” : AUGURE, RIRES ET RÉGÉNÉRATION DANS LA POLITIQUE TRADITIONNELLE (PACOTA, HUAROCHIRÍ)}

\section{Resumé}

Une variante du jeu d'oracle pichca, différente de celles décrites par Gentile Lafaille (1998), procure une augure annuelle pour l'agropastoralisme dans la région centrale de Huarochirí (département de Lima, Pérou). L'aspect ludique prédomine, mais les croyances et agissements associés à ce jeu ont également des conséquences pratiques. Aujourd'hui, comme dans le manuscrit quechua de Huarochirí de 1608 [?], un schéma de dualisme alternant sert à régénérer l'ordre politique face aux impondérables climatiques et historiques.

Mots clés : Ethnographie, ethnohistoire, religion, rites, jeux, Huarochirí.

* Se agradece cordialmente a las siguientes instituciones que apoyaron la investigación: Instituto de Estudios Peruanos, John Simon Guggenheim Memorial Foundation, National Science Foundation y Wenner Gren Foundation. Se agradece igualmente la cordial hospitalidad del Consejo Municipal y a los pobladores de San Juan de Pacota, anexo de Tupicocha. Agradezco cordialmente a Mercedes Niño-Murcia y a Sophie Watt por su ayuda en cuestiones de traducción y estilo. Las fotos y diagramas se reproducen con permiso del autor.

** Department of Anthropology, University of Wisconsin-Madison, 5240 Social Science Building, 1180 Observatory Drive, Madison Wisconsin 53706-1393, EE.UU. E-mail: fsalomon@facstaff.wisc.edu 


\title{
“HUAYRA HUAYRA PICHCAMANTA!”: AUGURY, LAUGHTER, AND REGENERATION IN AN ANDEAN POLITICAL REGIME (PACOTA, HUAROCHIRÍ)
}

\begin{abstract}
A variant of the oracular game pichca, different from variants described by Gentile Lafaille (1998), provides an annual augury for agropastoralism in central Huarochirí (Department of Lima, Peru). It is playful, but beliefs and practices around it also have practical consequence. Today as in the Huarochirí Quechua manuscript of 1608 [?], a pattern of alternating dualism serves to regenerate political order in the face of climatic and historical imponderables.
\end{abstract}

Key words: Ethnography, ethnohistory, religion, ritual, games, Huarochiri.

En 1998, Margarita Gentile Lafaille publicó en el Bulletin de l'Institut Français d'Études Andines el estudio más compendioso hasta ahora realizado sobre el juego ritual andino pichca. Demostró su extraordinaria difusión a través del espacio cordillerano, que alcanza hasta las últimas periferias ecuatorianas, chilenas y argentinas del ex Tawantinsuyu. Además comprobó su no menos impresionante persistencia a lo largo del tiempo, desde una época prehispana todavía indefinida, por falta de cronología radiocarbónica, hasta la actualidad. El elemento material central en el polifacético juego de pichca ('cinco') es un dado en forma de pirámide truncada (González Holguín, 1952[1608]: 284), el cual es tirado por los jugadores dentro de una cancha o espacio ritual cuyo diseño varía según regiones.

Gentile demuestra que las funciones modernas de la pichca varían entre la funeraria y la lúdica. La pichca figura en numerosos testimonios etnográficos como elemento del velorio de los muertos, en cuyo contexto el nombre pichca 'cinco' posiblemente tenga relación con las cinco trasnochadas que iniciaban en el tránsito al otro mundo (Carter \& Mamani, 1968: 335-337; Belleza, 1995: 133; Duviols, 1986: 270; Juan \& Ulloa, 1978[1748], I: 549; Rivet, 1927; Karsten, 1930a; 1930b; Nordenskiöld, 1930; Hartmann \& Oberem, 1968; Labarre, 1969[1948]: 136; Paerregaard, 1987: 2527; Valderrama \& Escalante, 1980; Roca Wallparimachi, 1955). En cambio, cronistas tales como Cobo (1964[1653], II: 86), Garcilaso Inca (1985[1609], I: 90) Murúa (1946[1590]: 223), y Guaman Poma (1980[1613]: 217) afirmaron que el juego del dado andino fue diversión lúdica de señores y damas inkas. En los casos modernos observados en Argentina por Lafaille también predomina la nota lúdica. La diferencia, sin embargo, es gradual y no dicótoma. Arriaga (1968[1621]: 216) comentó que la pichca servía de diversión durante el velorio. Hoy en día también el juego funerario es a la vez jocoso y un poco sagrado (porque las fortunas al azar de los herederos revelan algo sobre la suerte o la voluntad del ser desaparecido).

El presente ensayo subraya la presencia de la pichca en un contexto menos enfatizado por Gentile, a saber, el proceso político en su faceta de reproducción simbólica. El caso toma interés por enfocarse específicamente en las alturas de Huarochirí, zona donde el manuscrito quechua de 1608 [?] (Taylor, 1987) y los actos de "extirpación" surten un contexto histórico enriquecido. 
El caso se presenta con miras a una interpretación más que local. Si es que algún rasgo cultural merece el calificativo de "panandino" la pichca figuraría entre los candidatos fuertes para tal categoría. Sin caer en la trampa de suponer que una estructura difundida necesariamente tenga la misma función en todas sus instancias, podemos preguntarnos si las instancias etnográficamente conocidas no dan alguna pista para saber por qué este "juego" no se limita a lo lúdico sino que articula pasajes importantes de los grupos sociales: entre vida y muerte, entre actividad de mitades anan y urin, y entre ciclos políticos.

\section{EL JUEGO DE PICHCA EN HUAROCHIRÍ}

La práctica oracular de un augurio similar a la pichca en Huarochirí queda documentada desde fechas anteriores a la extirpación de "idolatrías". Un informe de la pionera misión jesuítica en Huarochirí (1571), firmado por Juan Gómez, describe el juego bajo el nombre de jhanca, posiblemente utilizando el término propio del idioma étnico de la región, con afiliación Jaqaru o Kauki (Adelaar, 1994; Taylor, 1983).

“... tienen una piedra pequeña q. se llama jhanca quees ynterprete del ydolo mayor esta piedra tiene vna señal en la una parte. y despues q. adoran. al ydolo mayor q. se lllama guaca echan. esta piedra. como quien echa dados. y si sale la señal dizen q. se les conçeden [sic]. lo que piden. y si no se les conçede enpiezan allorar y [sic]. y entonzes hazen sacrifiçios para aplacar al ydolo..." (Polia Meconi, 1999: 199).

En 1611 el P. Francisco de Avila informó extensamente sobre un oráculo huarochirano en el cual se arrojaban dos piedras llamadas chanca y cunchur (Arguedas \& Duviols, 1966: 255-257). El apelativo cunchur aparentemente equivale a con churi, término referente a ciertos "ídolos" transmitidos en herencia patrilineal, y utilizados para sacar augurios en el diálogo con huacas mayores (Taylor, 1987: 236-237, 502503). La caída de la piedra chanca reveló el oráculo del cunchur. Del augurio recibido se decía, según Avila (256), himinmi, 'Es su voz' o 'Es su palabra' [i.e., de la deidad] (1). Esta idea se mantiene vigente en los hechos etnográficos expuestos a continuación. El juego descrito abajo aparentemente fusiona elementos del antiguo augurio huarochirano chanca / cunchur (dualidad de objetos divinatorios, consulta explícita a las deidades) con otros propios a la pichca más ampliamente difundida (dado en forma piramidal, terminología relacionada con el vocablo wayru).

El contexto para el juego en el Huarochirí de hoy no es funerario ni exactamente lúdico, sino político. Su escenario es la reunión plenaria de la comunidad, llamada Huayrona. La Huayrona se efectúa en el día de año nuevo o en los dos días siguientes. Se practica en la misma zona del centro de la provincia de Huarochirí, cuyos ayllus fueron hace cuatro siglos protagonistas, como también autores orales de la fuente quechua. Cada pueblo realiza su Huayrona en un recinto ritual especial, generalmente llamado la collca. Durante la Huayrona las autoridades salientes rinden cuenta de su

(1) Himinmi: morfológicamente, himi es variante de simi 'voz,' 'boca,' o 'palabra'. - $n$ es marcador de posesión de tercera persona. -mi es validador de testimonio ocular. 
actuación pasada, y las nuevas entran conversando con los comuneros sobre sus planes para el futuro. De manera más o menos paralela el cambio de mando se realiza al interior de cada una de las parcialidades o ayllus que, conjuntamente, constituyen la comunidad. Es importante observar que la meta de la Huayrona es la de fenecer un ciclo sin residuos e inaugurar el nuevo en tábula rasa. Al interior de los ayllus, las cuentas monetarias tanto como las morales deben quedar en cero al instante del cambio de ciclo. Plasmar este estatus de cumplimiento sin rezagos, probablemente fue la meta del espectáculo de los khipus o quipocamayos de parcialidad, cuya transferencia a los nuevos Presidentes de Parcialidades forma el clímax de la Huayrona de Tupicocha (Salomon, 1997; 2002).

¿Por qué la Huayrona se llama Huayrona? Wayru fue el nombre ritual del valor "uno" - "el as", como lo explica Gentile Lafaille- dentro de la versión inka del juego. Bertonio (1984[1612]: 157) define huayrusitha como sinónimo del verbo aymara piscasitha, o sea 'jugar pichca'. Guaman Poma (1980[1613]: 217) menciona conjuntamente con la pichca un juego "uayro de ynaca", posiblemente de mujeres. Según Cobo los inkas se holgaban jugando "la pichca, que es algo modo de dados... y echando el dado el rey, dijeron a voces todos los presentes Guayro, Guayro" (1964[1653], II: 86). Dando interpretación quechua, la forma hipotética * wayruna habría significado 'lugar u ocasión apta para hacer wayru', o sea, jugar la pichca.

Entre paréntesis, los lectores limeños habrán observado el vocablo HUAYRONA pintado en carrocerías de ciertos buses urbanos que pasan a pocas cuadras de la casa limeña donde se edita la presente revista. Estos tienen por terminal una urbanización del mismo nombre en el Valle de Lurigancho. No se sabe si tal topónimo urbano se arraiga en que el dicho lugar alguna vez fue local para reuniones con pichca, o si en cambio el nombre fue importado por los constructores. La primera posibilidad no es de descartarse, tomando en cuenta el hecho de que "Ruricancho" figura entre los lugares cuyos aborígenes yuncas tomaban parte en el régimen ritual descrito por la fuente quechua (Taylor, 1987: 188-189). El nexo geográfico es estrecho; hoy en día las últimas urbanizaciones luriganchinas incursionan en el espacio político de la provincia de Huarochirí. El vocablo huayro penetra adicionalmente en la cotidianidad limeña como nombre de una variedad popular de papa, cuya forma alargada puede haberse comparado metafóricamente con el dado del juego de este nombre.

La reunión cívica huarochirana incluye una variante del juego pichca hasta hoy, pero en pocos lugares. En Tupicocha, el juego figuraba como parte de la plenaria pueblerina hasta la década de 1930. En 1935, Tupicocha obtuvo reconocimiento estatal en calidad de comunidad indígena (hoy comunidad campesina), y en 1941 la categoría municipal de capital de distrito. Posiblemente como parte de las reformas modernistas que acompañaron la transición a estas dignidades, Tupicocha dejó de practicar el juego.

Sin embargo, respetando "la costumbre" (frase que localmente implica la ley consuetudinaria y no meramente la idiosincrasia cultural), los tupicochanos delegaron el augurio a su satélite, el recién fundado "anexo" de Pacota (AMSAT/SAT, 6: 132, 147). La aldea de Pacota hasta hoy realiza un augurio considerado como válido para el distrito entero. Uno de los dados (el mayor, llamado "el macho") lleva las inscripciónes "AM" y "1935". Es posible que "AM" sea las iniciales del donante que presidió el traspaso de la pichca a Pacota o que donó los reemplazos de los dados tupicochanos. 


\section{LA HUAYRONA DE PACOTA (1 DE ENERO 2000)}

Los párrafos que siguen demuestran la estructuración del oráculo como componente de una estructuración mayor, homóloga en todos sus aspectos y niveles, tanto en la diacronía como en la sincronía.

El espacio público pacoteño consiste de una simple plaza sin construcción alguna, de forma rectangular. Es bordeado por varias casas particulares, y por los dos lados largos, por la iglesia y la ya mencionada casa comunal de reuniones o collca. Para las ceremonias del año nuevo, se redefine y adorna el espacio público para manifestar su división en dos grandes componentes. Un componente es la misma collca, arreglada de la forma descrita abajo. El otro es la cancha del juego-augurio pichcamanta. Se construye en la plaza, exactamente en frente de la casa comunal y con dimensiones aproximadamente similares. Sus particularidades también son descritas abajo.

A grandes rasgos, el programa del día abarca una transición de la primera a la segunda mitad del espacio dicotomizado. Esta transición es intrincada, y sus características demuestran una hermanación o simetría en espejo que asimila el proceso político al proceso lúdico-ritual.

La collca (Fig. 1) (2), es entonces el escenario de la primera mitad del ciclo ceremonial. Es un gran galpón techado, en donde se reúne el Consejo de la Municipalidad Menor de Pacota. Para la Huayrona, se arregla el interior de la forma indicada en la figura 2 .

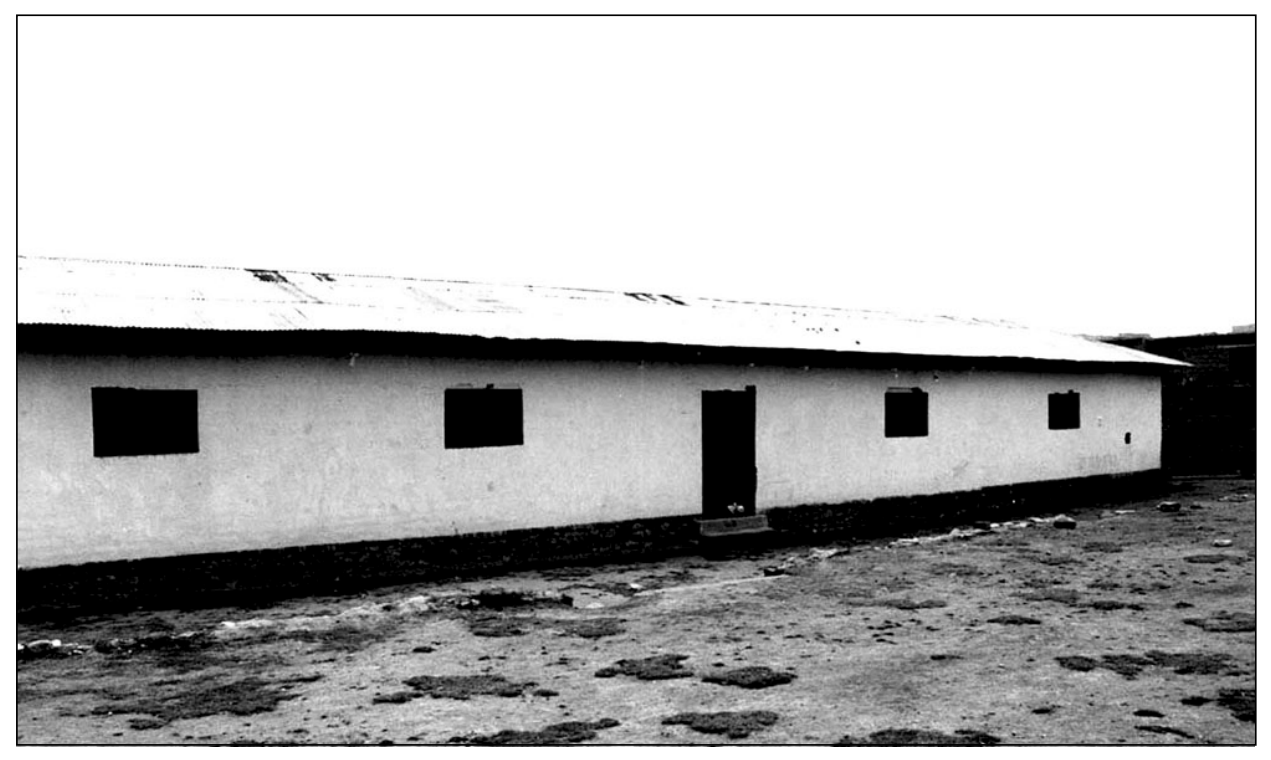

Fig. 1 - El local comunal o collca de Pacota, 1 enero 2001. Las "casas de costumbre" o collcas de Huarochirí central comparten con las kallanka inkas la forma rectangular alargada con aperturas hacia sólo un lado.

(2) Fotografías y diagramas reproducidos con permiso del autor. 


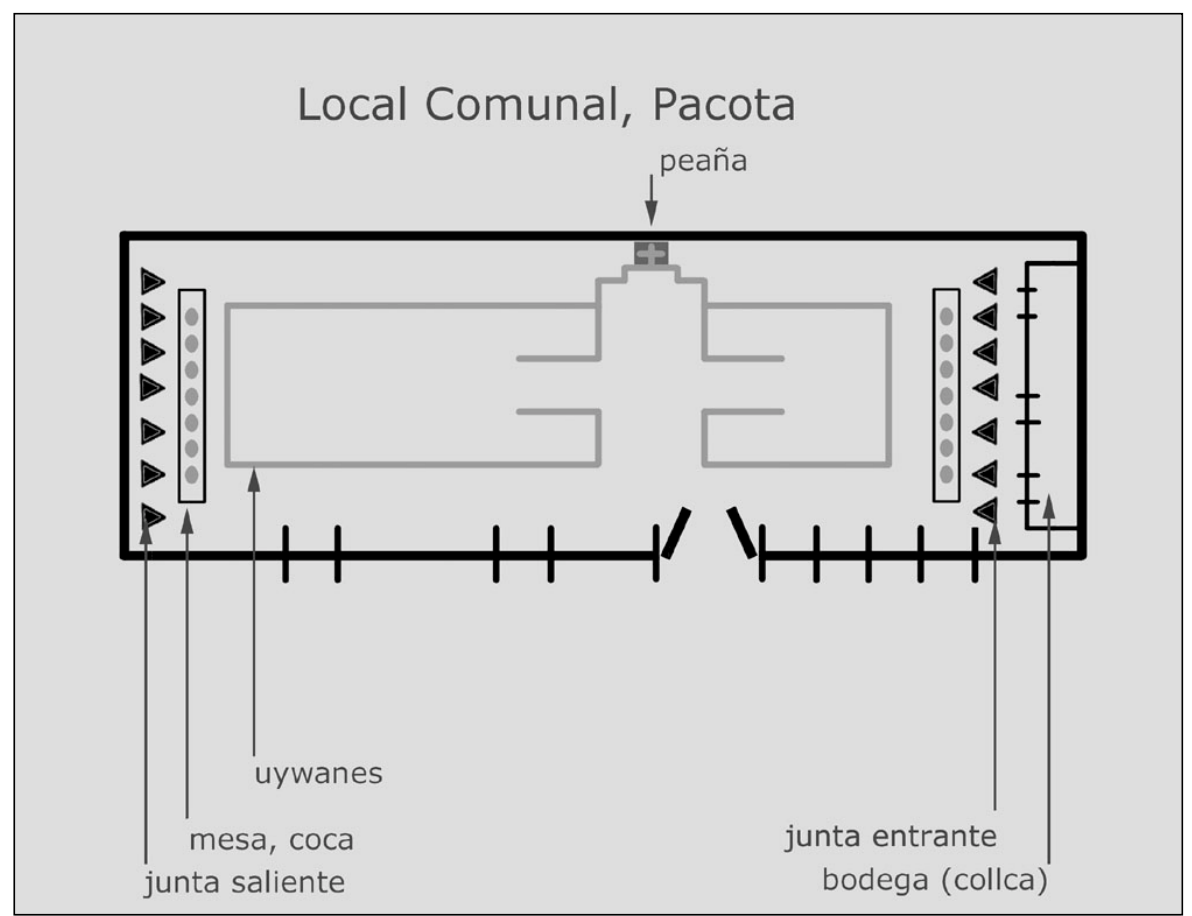

Fig. 2 - Plan del interior de la collca, indicando el despliege de las respectivas mesas de autoridades y de comuneros y de los objetos sagrados. El esquema no es proporcional a las medidas del edificio.

El interior de la collca es, a su vez, dicotomizado. La Huayrona comienza por la mañana con los autoridades salientes como anfitriones, sentados en la mesa derecha (desde el punto de vista de quien entra por la puerta) delante del depósito comunal (collca en su sentido etimológico). El escenario se aprecia en la figura 2. El público de comuneros se sienta cara a cara con ellos, separados por una considerable distancia, al otro extremo, en una mesa simétrica. En ambas mesas predominan hombres, pero las mujeres que encabezan unidades domésticas en derecho propio, o que representan a sus maridos ausentes, también se hacen presentes. Dos músicos se sientan un poco aparte. Previamente a la reunión los varayos y ordenanzas (portadores de bastones de autoridad y ayudantes a las autoridades) han preparado el espacio intermedio como recinto sagrado, de la forma indicada en la figura 3. El espacio sagrado queda demarcado por manojos de hierba fresca recién traída de las alturas (guayllabanas o catahuas) que en el contexto de la reunión son llamados uyhuanes (Fig. 3). El escrupuloso cuidado manifestado en la preparación y el uso coreográfico de la paja fresca durante la ceremonia entera hace pensar en un detalle del mencionado informe de 1611, donde Avila observa que se reservó para el cunchur un lugar de honor "con una poca de paja fresca". 


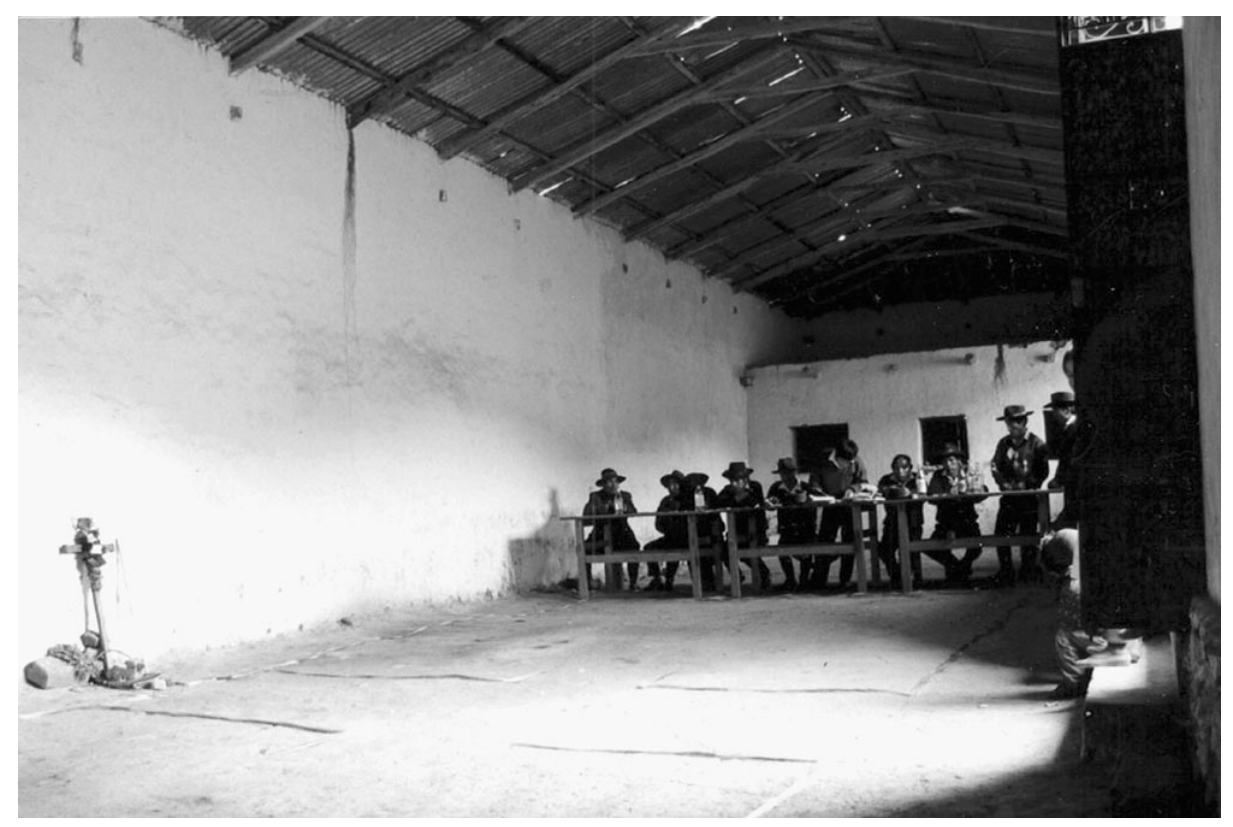

Fig. 3 - Las autoridades salientes, los uyhuanes o manojos de paja de puna que demarcan el espacio sagrado y, al fondo, el depósito. Al entrar, por la puerta visible a la derecha, cada persona debe avanzar por la vereda central, hacer la venia ante la peaña (izquierda), retroceder y pasar a su asiento siguiendo la periferia.

Los vocablos catahua y guayllabana son dos de los numerosos hispanoquechuismos huarochiranos cuyas derivaciones resultan opacas a los actuales huarochiranos porque son hispanohablantes monolinguies. (Ya que dichos vocablos forman parte del español y no del quechua, se escriben aquí con la ortografía vernácula.) Catahua no aparece en los diccionarios, pero quizás puede relacionarse con el verbo Katani 'cobijar o techar' (Gonçález Holguín, 1952[1608]: 138) porque la catahua es parecido al manojo de paja que se ata al listón para hacer techo. Guayllabana aparentemente se relaciona con "Huaylla El prado verde no agotado, o el buen pasto" (Gonçález Holguín, 1952[1608]: 192). -bana no tiene étimo plausible en los diccionarios quechuas ni aymaras. Puede ser que el vocablo derivó por síncopa de la frase *waylla uywana, cuyo significado resultará más claro al tomar en cuenta la palabra moderna uyhuán.

El vocablo uyhuán no se usa fuera del contexto ritual. Los lugareños desconocen su origen. A nivel de conjetura, se puede comparar con "huyhuaccuna. Todas maneras de crías... de animales y arboleda criado a mano..." (Gonçález Holguín, 1952[1608]: 205; ver también Lira, 1982[1941]: 310). La forma singular de este sustantivo, marcado con sufijo de poseedor tercera persona - $n$, habría sido *huywan, o sea en ortografía vernácula moderna uyhuan. La glosa evidente es 'su cría', i.e. la cría del cerro deificado. (El cerro divino que surte agua a Tupicocha es una parte de la cordillera de Pariacaca que se llama Villcapampa, cerca del sitio minero Germania.) Es frecuente en varios 
contextos huarochiranos hablar de lo que parece salvaje o silvestre desde el punto de vista del agricultor, como si fuera la cría o pertinencia doméstica de los seres sobrehumanos (p.e. el llamar el puma 'su gato'). Los uyhuanes serán, pues, la cría vegetal, o sea la chacra de los seres divinos. El espacio bordeado con uyhuanes es en efecto la réplica microcósmica del cerro divino. Esta idea parece implícita en la atención con que se coloca a los uyhuanes con orientación definida. Cuando forman aspas, la raíz de la paja tiene que ponerse hacia la periferia, para que su parte alta y verde apunte hacia la cumbre simbólica del espacio, o sea, su peaña.

La paja entonces define un recinto inviolable. Al ingresar, cada persona avanza por la vía abierta hasta hacer su venia ante la cruz, antes de retroceder por la periferia y sentarse. Solamente el "ordenanza" o auxiliar de las autoridades es autorizado a pisar las dos áreas que flanquean la cruz. Lo hace para dirigir mensajes individuales a personas de cualquier lado.

$\mathrm{Al}$ extremo derecho de la línea divisoria (desde el punto de las autoridades) se sitúa la "mesa" (en realidad, un manto tendido). En ella son depositados los objetos consagrados que se van a describir abajo. Las autoridades salientes hacen distribuir a los asistentes los acostumbrados regalos del "enfloro" (inauguración de contexto ritual): hierbas aromáticas, seguidos por hojas de coca, tabaco y trago. Los regalos se repiten en cada pausa u "hora de costumbre" (Fig. 4)

Los objetos rituales que consagran la ocasión se aprecian en la figura 5. En conjunto, constituyen la "peaña" o santuario, elemento imprescindible para convocar cualquiera ceremonia huarochirana. El vocablo "peaña" sensu strictu se refiere a la pirámide de gradas que forma la base de la cruz. En este caso la peaña piramidal se inscribe en el espacio mediante la disposición de los uyhuanes según se ve en la figura 2.

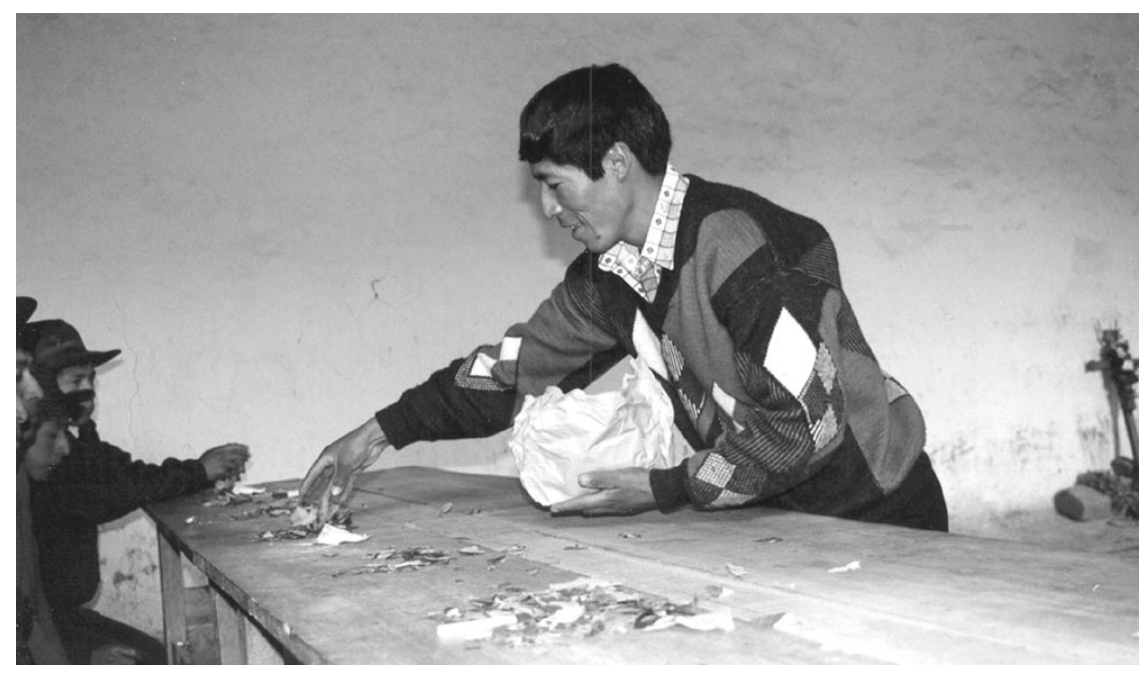

Fig. 4 - Al igual que en la fuente quechua de 1608, las autoridades en contexto ceremonial hacen distribuir la hoja de coca. En esta foto el ordenanza (diputado) de las autoridades salientes honra a los comuneros visitando su mesa. 


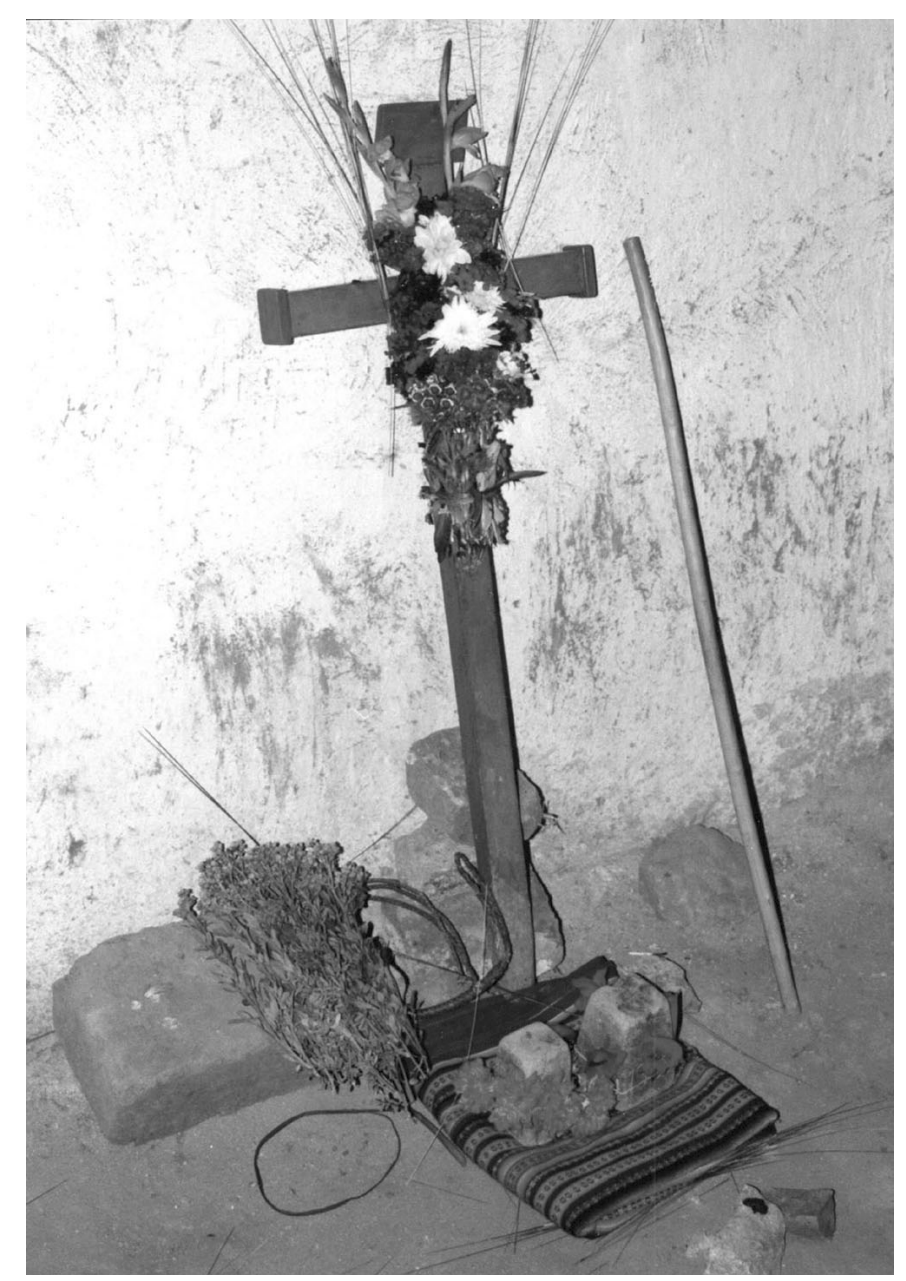

Fig. 5 - Los objetos sagrados de la Huayrona incluyen la "cruz de trabajo", la "seplina" (i.e. chicote o disciplina) que es insignia de la autoridad política, una vela sobre la piedra de la peaña, un uyhuán de paja de puna, hierbas de romero para el "enfloro", la vara del regidor, y los "troncos" o dados del juego-oráculo. En conjunto con los uyhuanes, conforman la peaña o santuario de la ocasión.

La primera mitad del ciclo, la reunión cívica, es dividida en mitades, o sea, cuartos del ciclo global. Después del "enfloro" inicial, las autoridades salientes rinden cuenta sumaria de sus actividades, contestan preguntas de los comuneros, cierran las cuentas del año pasado y organizan la elección de nuevas autoridades. Una vez realizados estos quehaceres, se sigue una pausa para consumir la coca y para bailar en fila, con un simple paso rítmico, alrededor del recinto sagrado. Durante la segunda mitad, el orden espacial se invierte. Las nuevas autoridades pasan a la mesa directiva, mientras que los salientes cruzan al otro lado — siempre por la periferia— para ocupar 
la mesa de los comuneros. Los nuevos dignatarios toman sus juramentos solemnes y se dirigen al público con breves discursos en pro de las mobilizaciones necesarias para mejorar la infraestructura productiva durante el año entrante.

Con estos actos se finaliza la primera mitad del ciclo y se pasa al segundo. Como toda transición estructurada a la tupicochana, esta no es instantánea ni abrupta, sino implica pausa intermedia para bailar. Siendo más decisiva la transición, el baile es también más largo y más formal. Cada comunero recoge con las manos un uyhuán de los que demarcan la periferia. Todos bailan en fila varias vueltas por la línea de la periferia, con gritos de triunfo al haber cumplido con el deber.

El traspaso de los uyhuanes del espacio interior al exterior se considera crucial. Llevar un uyhuán y mantenerlo erguido durante el baile y el juego, es auspicioso para el comunero. Al contrario, el dejar pajas de uyhuán en el suelo interior, o dejarlas caer al bailar, o portarlas en posición menos que vertical, son faltas y serán amonestadas por las autoridades. El objetivo es la perfecta transferencia y superposición congruente del contexto cívico interior al espacio lúdico-ritual del exterior (Fig. 6).

\section{EL JUEGO DE HUAYRA HUAYRA PICHCAMANTA}

El movimiento definitivo de la transición es la levantada de la mesa y transporte de los "troncos" o dados (Fig. 7) por las nuevas autoridades desde el interior al exterior, donde una orquesta local les saluda músicalmente.

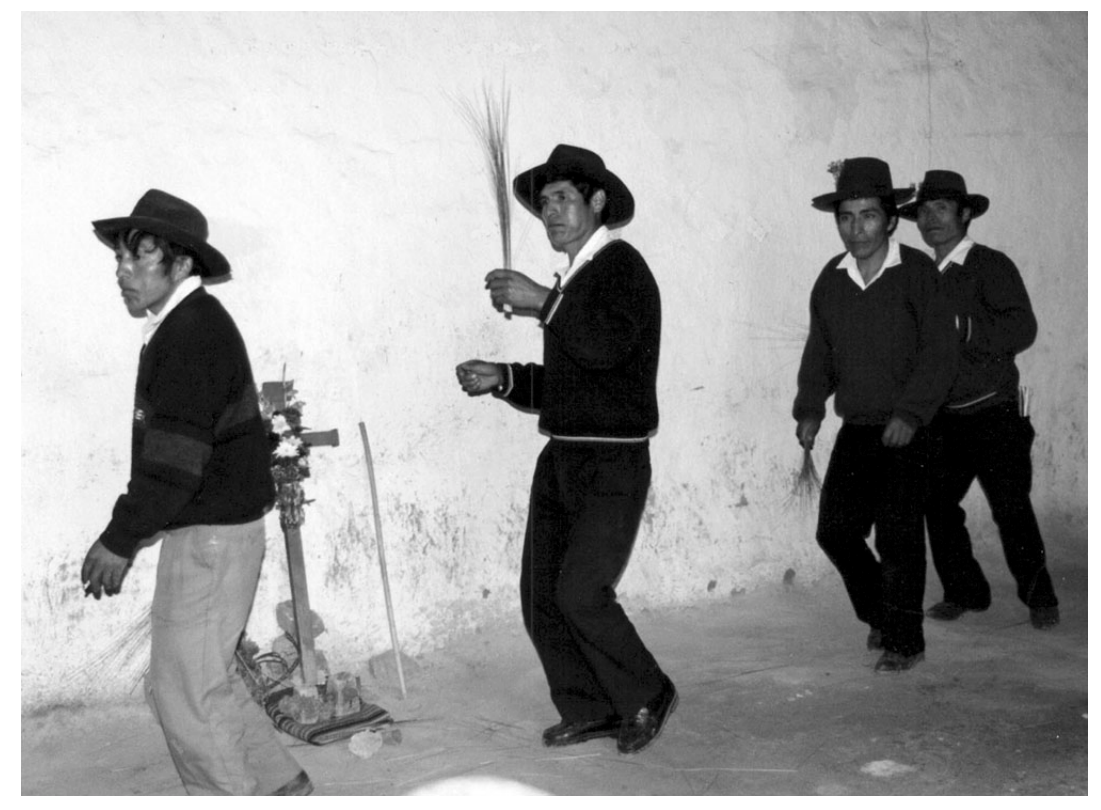

Fig. 6 - Al cerrar la plenaria cívica, los ciudadanos levantan los uyhuanes del recinto sagrado y bailan para preparar la salida a la cancha del juego-oráculo. Se considera muy importante no desperdiciar la paja consagrada. 


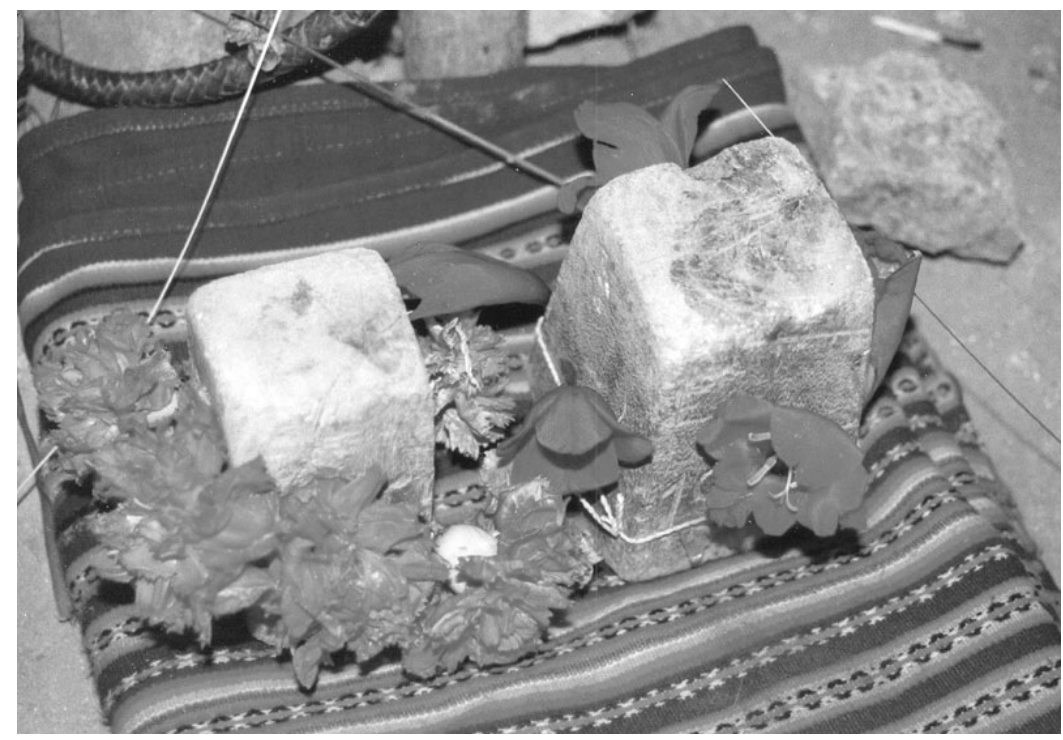

Fig. 7 - Los "troncos" llamados "hembra" (izqierda) y "macho" (derecha) en su "mesa" esperan el transporte a la cancha. Son de madera y miden aproximadamente $14 \mathrm{~cm}$ de altura. El adorno con flores implica reverencia.

Las flamantes autoridades lideran la procesión del galpón al aire libre, donde el sol del artardecer ya decae. La plaza, al igual que la collca, ha sido demarcada previamente como recinto sagrado (Fig. 8). Los comuneros, sus invitados y esposas bailan numerosas veces alrededor, teniendo en alto los uyhuanes. Durante este intervalo las botellas surtidas por las autoridades circulan rápidamente, ya que la embriaguez se considera la condición propicia para el juego.

A diferencia del espacio interior, el recinto sagrado del juego no ofrece entrada para que las personas laicas pisen el espacio sagrado. Los únicos habilitados para entrar en él son los infaltables payasos-autoridades, siempre presentes en los ritos huarochiranos de la temporada de lluvias. En este caso son dos, disfrazados y nombrados respectivamente como "gato" (i.e. puma) y "soldado". Son los oficiales del oráculo, mediadores entre los jugadores y los poderes sobrehumanos cuya comunicación se proponen obtener. El "gato" o puma figura en numerosos contextos rituales y míticos (notablemente en la "matanza del gato", cada 8 de enero en Tupicocha) como encarnación de las poderes de lo periférico, lo precultural, y de la altura. El soldado representa por excelencia los poderes de lo "civilizado", el estado, la ciudad y la costa. Hasta cierto punto hacen eco del tema tan repetido en el texto quechua y en la mitología de los yauyos invasores que mitológicamente depredaron y conquistaron tierras de los yuncas de los valles.

El juego de augurio, como la reunión cívica, mobiliza las mitades en padrón alternante. En el comienzo, los dados "macho" y "hembra" son colocados sobre la "mesa" en el extremo desde donde tirará el equipo de las autoridades salientes. Los salientes inician el juego desde el extremo "sierra" y los entrantes desde "costa" (Fig. 9). 


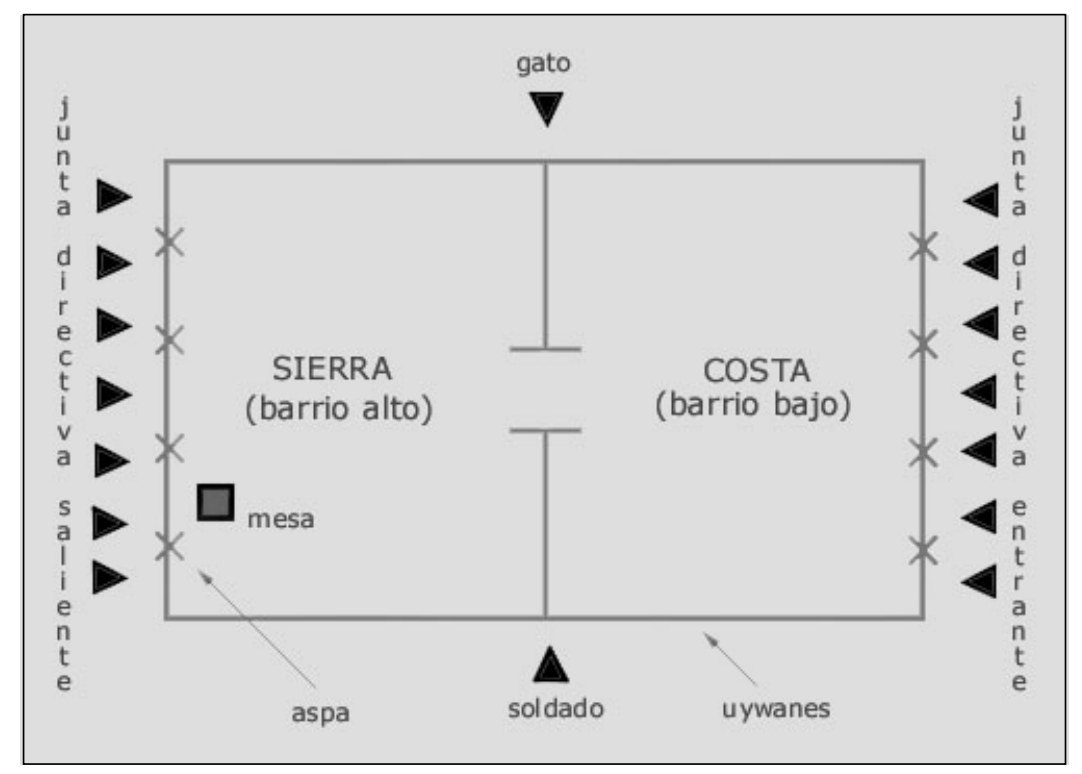

Fig. 8 - La cancha del juego ceremonial. "Mesa" significa el descanso inicial de los "troncos".

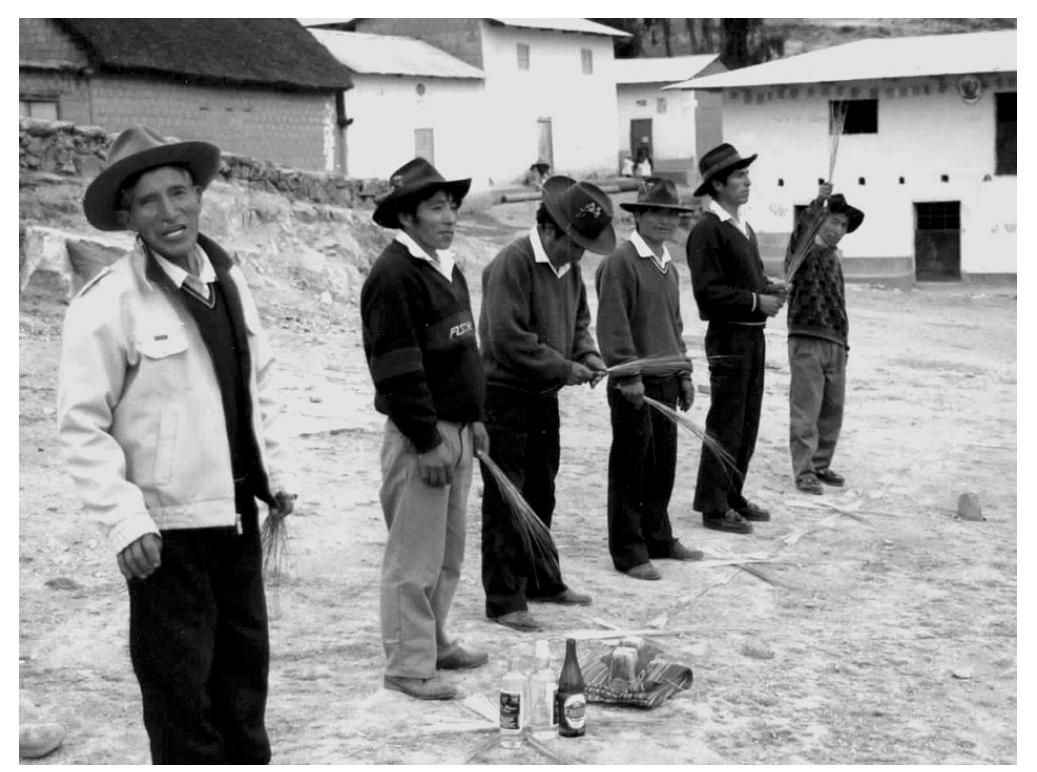

Fig. 9 - Las autoridades salientes se alistan para empezar las jugadas de los "troncos". Tienen en las manos los uyhuanes traídos desde el interior de la casa de reunión. 
En este momento los dos presidentes pronuncian las invocaciones. Pueden ser extensas, pero su contenido es sencillo y se suma en ciertas frases y figuras repetidas:

"Hemos cumplido con el deber del orden de costumbre. Nuevamente rogamos encarecidamente a los hermosos Dueños, que nos manden agua suficiente para nuestros cultivos, para nuestros ganados, para las flores silvestres de la tierra. Trabajemos con cuidado (3), como un solo hombre, para que la tierra nos sustente bien durante todo el año que empieza hoy."

A veces se alude a los proyectos de mejora de infraestructura u otros empeños comunitarios, y se exhorta para mejor cumplimiento en las faenas.

Estos poderes son la pareja de deidades llamados "dueños" del agua. Son los mismos personajes festejados en la "champería", o limpia acequias cada año al finalizarse la temporada de lluvias. Se llaman Pencollo y Mama Capyama o María Capyama. Tienen por manifestaciones físicas ciertas calaveras altamente sagradas, que se conservan en un lugar secreto. En la champería, los “dueños" saludan a sus protegidos con las palabras de una "carta" (en efecto preparada por sus sacerdotes los Huaris, bajo influencia de la inspiración divina). En el año nuevo, el discurso de los jugadores se dirige a ellos, y a los nevados de la cordillera de Pariacaca, para que den su respuesta bajo la forma del augurio.

Los "dueños" dan su respuesta haciendo que los dados se caigan o se paren de pie. Las paradas afirman que mandarán lluvia. La mitad donde los "troncos" se paran — “costa" o "sierra" - indica donde caerá la lluvia. Las paradas no son de igual valor sino que demuestran todos los atributos del clásico dualismo andino: similitud de forma y complementariedad de función, con desigualdad de rango. El dado "macho" es algo más grande y su forma piramidal está algo más marcada. Debido a esta propiedad, se para más fácilmente que la "hembra" al rebotar en el suelo. El valor ritual del "macho" se considera como menor que el de la "hembra". La parada de esta se realiza con tanta dificultad que al forastero le parece casi aleatoria; o sea, que su comportamiento refleja menos la destreza humana y más la voluntad divina. Ambos dados prometen lluvia, pero la "hembra" promete más lluvia y es más certera.

El juego de huayra huayra pichcamanta, o pichcamanta según la usanza de la localidad, se realiza en dos períodos. Cada período se subdivide en dos jugadas: la del "macho" y la de la "hembra".

La primera tirada del primer período es del presidente saliente, y utiliza el "tronco macho". El tirador se posiciona justamente al exterior del recinto. Grita “ „Huayra huayra pichcamanta!” y arroja el tronco al aire (Fig. 10). El que arroja puede apuntar para "sierra" o "costa", pero el rebote irregular del dado hace de su propósito una apuesta muy incierta. Luego, sucesivamente cada miembro o invitado de los salientes toma su turno, siempre con el mismo grito. Es ocasión para gritos, saludos cálidos y bromas con los payasos-oficiales en el rol de cómicos principales. El clima social no es solemne sino efervescente y solidario. Los dos equipos no se burlan entre sí, ni importa para nada cuál equipo tira mejor.

(3) i.e. cuidado de no desperdiciar agua. 


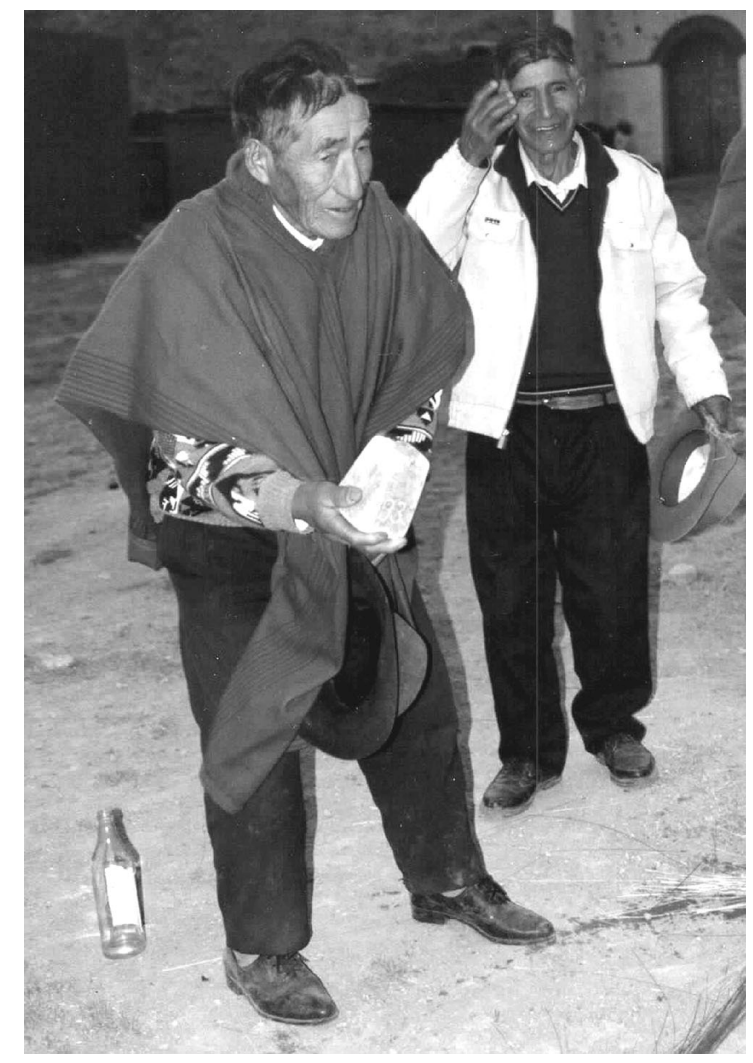

Fig. 10 - Don Gregorio Javier se prepara a tirar el dado "macho".

Los jugadores dicen ignorar el significado del grito. Si se entiende como frase quechua, su significado habría sido algo como “ $j e l$ as, el as de los cinco!” (o "desde los cinco", tomando en cuenta de manera más estricta el significado del sufijo-manta). Ya que no importa en la versión huarochirana cuál de los cuatro laterales sale arriba en caso de que el dado no se pare, tal frase no tendría relevancia práctica y es comprensible que su traducción se haya olvidado. También existe cierta indeterminación en cuanto a su pronunciación, que a veces suena como "huira huira". Los documentos comunales observados no mencionan el grito. Tampoco se han detectado vinculaciones semánticas suficientes para afirmar un vínculo con wira (morfema presente en el nombre del ser divino Cuni Raya Huira Cocha de 1608), ni con wayra ("viento"). El último parece improbable porque el viento de por sí no se considera como recurso.

En el momento que el dado toca tierra, el "gato" en "sierra" o el "soldado" en "costa" brinca alrededor y anuncia si cae o para (Figs. 11, 12). Los payasos-oficiales tienen la decisión sobre el número de turnos que cada equipo puede tomar. Si un "tronco" se para, el turno pasa al otro equipo. Si no, los oficiales deciden cuándo.

Desde "costa", el equipo de los entrantes toma sus turnos de la misma manera. 


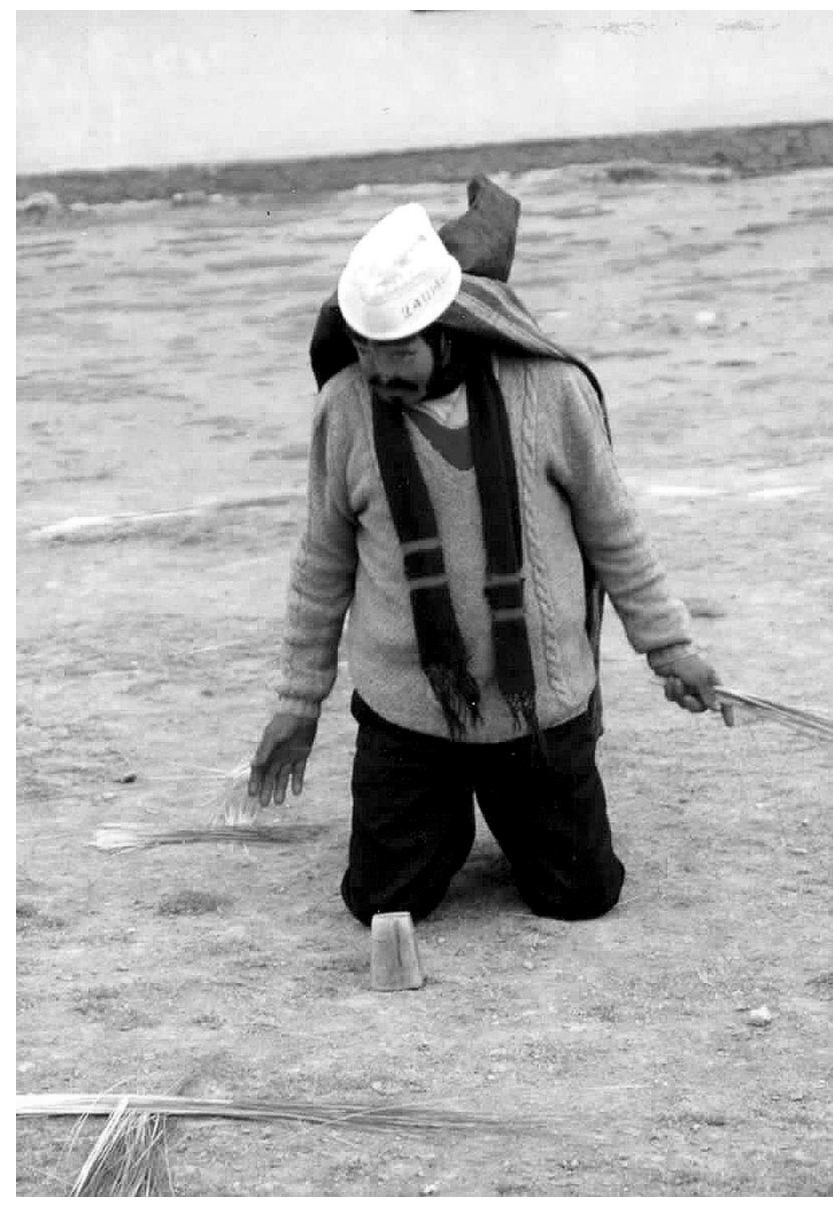

Fig. 11 - El "gato" enmascarado confirma que el tronco "macho" se paró en la parte "costa", dando augurio de lluvia.

En cierto momento, los payasos retiran el "macho" y hacen repetir la secuencia entera utilizando la "hembra". Cuando se termina, los dos presidentes pronuncian discursos - ya más exaltados por el alcohol y menos coherentes — sobre el significado de los resultados.

Entre períodos de juego, como entre las mitades de la plenaria cívica, la comunidad baila alrededor del espacio sacralizado. Se inaugura el segundo período con las posiciones invertidas, o sea con los entrantes en la posición "sierra". Los payasosautoridades mantienen sus respectivas posiciones. Todo se repite hasta que la oscuridad y la borrachera marcan el fin, y los payasos-oficiales declaran el cierre.

En 2000, "macho" se paró en "costa” durante el primer período, y se produjo el mismo resultado en el segundo. "Hembra" no se paró. Tal pichcamanta fue interpretado como presagio de año fructífero para los frutales y las chacras bajas, y año magro para 


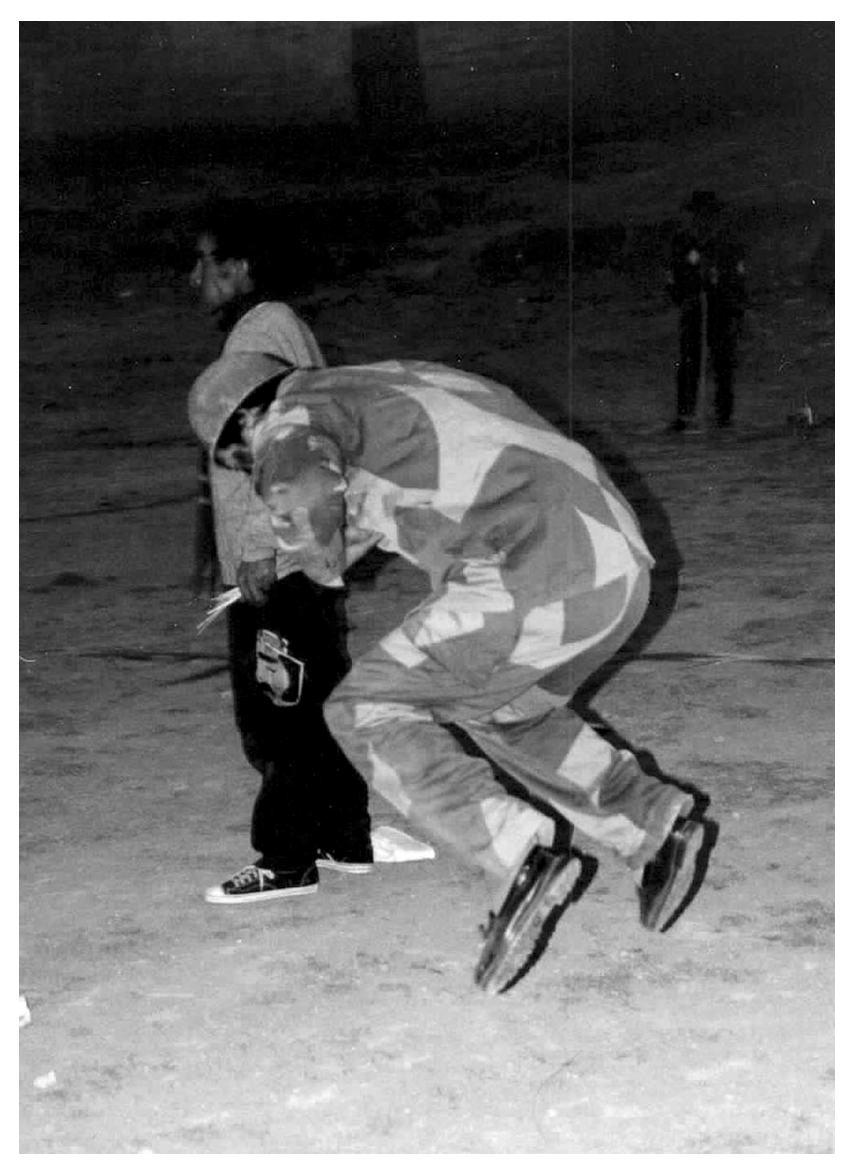

Fig. 12 - El "soldado" brinca de emoción al ver la buena tirada del tronco "macho". “Gato" y "soldado" son a la vez payasos y árbitros del juego-oráculo.

los pastizales y las chacras altas. Sin embargo el resultado no causó consternación porque, según los lugareños, la prosperidad de Pacota depende relativamente poco de las alturas de puna. Hasta cierto punto el augurio se interpreta como juicio emitido por los "dueños" de acuerdo a los méritos morales del pueblo durante el año pasado y la sinceridad de sus votos para el nuevo.

Sin embargo, no se considera ni se comenta cuál equipo tiró los dados parados, los entrantes o los salientes. Tampoco se considera que existan ganadores ni perdedores en el juego, excepto la colectividad como un todo. En cierto sentido, pues, no existe sino un solo jugador, la colectividad de Pacota. En vez de tensión y rivalidad, se produce un ambiente de fraternidad y risa. La borrachera que acompaña no conduce a peleas sino a chistes y abrazos, y cumulativamente mientras avanza la oscuridad, a la disolución de roles e identidades particulares en una efervescencia general e indiferenciada - la liberación de las energías sociales en la presencia de lo sagrado-. 
A pesar de la jocosidad, pichcamanta no es de broma. El resultado se toma más o menos en serio. No sólo en Pacota, sino en todo el distrito la noticia de los resultados pasa rápidamente de boca en boca. Cuando regresé a Tupicocha mi informe sobre el juego fue escuchado con atención por todos. Pregunté si tenían intención de considerar el pichcamanta al planificar sus respectivos usos de recursos. La mayoría dijo que sí, y que "el juego dice verdad las más de las veces". Unos pocos discreparon, diciendo "no tengo esa creencia".

\section{UN COMENTARIO: DUALISMO ALTERNANTE E HISTORICIDAD}

El juego oracular huayra huayra pichcamanta combina dos estructuras ampliamente difundidas en los Andes: la división del espacio en mitades opuestas, y la división del tiempo en intervalos interpretados como alternantes ( $\mathrm{A} / \mathrm{B}, \mathrm{A} / \mathrm{B})$, que en este caso se plasman en los períodos de actividad alternantes entre diferentes directivas o equipos políticos. Una cuestión digna de meditarse es ¿en qué consiste la articulación de los períodos?

Sostengo que el pasaje del tiempo A al tiempo B no es instantáneo. En numerosas esferas funcionales, desde la escala diminuta (pausas rituales con consumo de hoja de coca, llamadas "horas de costumbre", que separan las mitades de un período de trabajo) hasta la escala mayor de la reunión política totalizante, se crea un "tiempo fuera del tiempo" y un "espacio fuera del espacio" entre el fin de A y el comienzo de B. Todo el mundo habrá pensado cuán difícil es conceptualizar ese intervalo infinitesimal que se llama "ahora". El espacio y tiempo rituales constituyen una especie de "ahora" expandido, por excelencia en el año nuevo, dentro del cual se dramatiza y se hace visible el devenir, el carácter procesual e histórico de la actividad humana. Al contemplarlos, no pude reprimir la idea de que ese mismo rompecabezas que en la sala de seminario se llama "estructura y agencia", se exterioriza o dramatiza en contexto andino mediante el displiege lúdico de estructuras para inaugurar un ciclo de actividad.

En tales intervalos se activan las mitades A y B del tiempo - vale decir, un pasado y un futuro - articulando mitades de la sociedad (equipos) en mitades de espacio (canchas dicotomizadas).

Para los lectores de esta revista sería innecesario amontonar ejemplos de espacios rectangulares considerados como divididos en mitades para fines de rivalidad ritual. Los casos abarcan desde la plaza ritual del Cuzco de los inkas, en contexto de combates rituales, hasta la plaza de Macha (Bolivia) donde Platt (1986: 209) observó feroces contiendas entre las partes aransaya y urinsaya para "tomar la plaza" o las similares batallas en Cotacachi, Ecuador (ver casos adicionales en Palomino, 1971: 239-241).

Existen también amplios testimonios etnográficos sobre dualismos temporales, al parecer ampliamente difundidos por las culturas indoamericanas tanto en América del Norte como del Sur. En 1946 Curt Nimuendajú (90) documentó en The Eastern Timbira un sistema amazónico dentro del cual se dramatizó el paso del tiempo asignando alternadamente a las mitades de la plaza, este y oeste, la primicia para desplegar sus nuevos grupos de ingresantes. En los Andes, Harris (2000: 27) comenta la bipartición del año agropastoral aymara entre un ciclo de sequía, con acercamiento a los poderes de 
la altura y lo futuro, y otro de lluvia, con acercamiento a los de la profundidad y del pasado. Gose (1994: 157-170) informa sobre similares esquemas desde Huaquirca, en Apurímac.

La alternación en el tiempo sirve para organizar numerosos quehaceres productivos en colectividades andinas. En Cabanaconde, departamento de Arequipa, Paul Gelles ha estudiado detalladamente la competencia entre los alcaldes de riego de las mitades anansaya y urinsaya. Las mitades trabajan en las acequias alternando períodos de cuatro días, cada mitad con voluntad de superar a la otra gracias a la energía de sus esfuerzos (1995: 719-721). Igualmente en Huarochirí tiene su uso prosaico, como por ejemplo en el arreglo de los listados de turnos de agua que se despliegan frente a la plaza principal. El orden cronológico de los turnos, escrito en dos columnas, se ordena de derecha a izquierda en un mes y al revés en el siguiente. Como en la pichca, lo vigente o activo (mes en curso), y lo futuro o potencial (próximo mes) se turnan, ocupando espacios complementarios.

Volviendo a Huarochirí encontramos amplios ejemplos del mismo complejo. Según el manuscrito quechua de Huarochirí (Taylor, 1987: 351-393), los ancestros de los jugadores de la pichca unificaban componentes yauyo e yunca de su herencia cultural (Rostworowski, 1978) armando una alternación de festividades. Durante dos años se festejó la chuta cara, fiesta caracterizada por el baile de los ayllus de llacuaces o invasores, con las máscaras huayo hechas de caras humanas. Durante los dos años siguientes, se festejó la machua yunca, fiesta de origen yunca o huari, cuyo acontecimiento principal fue el torneo entre ayllus para lanzar dardos en grandes efigies macho y hembra. La machua yunca funcionó para dar augurio con respeto a los recursos de altura $\mathrm{y}$ de valle, y es posible que se haya fusionado con el anteriormente mencionado augurio de los cunchur y chanca para originar la pichca huarochirana moderna.

La dualidad alternante sigue siendo popular y versátil instrumento organizador en Huarochirí. En el cercano distrito de San Damián, las dos comunidades campesinas Concha y Checa alternaban tradicionalmente como anfitrionas de cierta fiesta. Santiago de Tuna, otro distrito vecino, asigna la fiesta de su santo patrón en años alternados a "barrio alto" y a "barrio bajo". En el mismo Tupicocha, desde los años 1940s, el santo patrón San Andrés y la santa patrona Vírgen de la Asunción presiden alternadamente el festejo patronal. Dos sociedades de baile, la Agrícola y la Sibimol, se turnan para organizar los festejos en enero, con las celebradas comparsas de curcuches o payasos sagrados que traen la bendición de los cerros.

Examinemos la articulación de los tiempos A y B en semejantes casos. Los principios son sencillos:

1. Cada ciclo de trabajo u otra actividad (tt...) se demarca estableciendo un intervalo ritual (rr..). Por ejemplo, cada mañana o tarde de trabajo, etc., tiene su "hora de costumbre": (tttt / rr / tttt).

2. Los módulos rituales y los períodos de otra actividad son marcados por consubstanciales mediante el traspaso físico de elementos materiales usados en cada rito, al período de trabajo subsecuente y vice versa. P.e. se llevan los implementos de trabajo a la "hora de costumbre" e inversamente se llevan las yerbas del "enfloro" al trabajo subsecuente. 
3. Cada ciclo es susceptible de subdividirse en mitades, estableciendo adicionales intervalos rituales en su interior: (tttt / $\mathrm{rr} / \mathrm{tttt})[\mathrm{RR}]$ ( $\mathrm{tttt} / \mathrm{rr} / \mathrm{tttt})$. Por ejemplo, como mencionamos arriba, la sesión cívica de la huayrona tiene en su interior mitades ritualmente demarcadas, y lo mismo tendrán las futuras reuniones posteriores al gran ritual de la pichcamanta. $\mathrm{O}$, diciendo la misma cosa de otra manera, cualquier unidad menor se considera como la mitad de algúna unidad mayor articulada por su intervalo: p.e. el año es considerado como unidad constituido por semestres articulados mediante la reunión llamado "seis-mes" y al interior de la reunión, mediante su respectivo módulo ritual.

4. El intermedio ritual pues constituye la bisagra entre el pasado y el futuro, lo realizado y lo potencial, lo determinado y lo contingente. En rituales de escala mayor, que articulan grandes segmentos de tiempo, se dramatiza las historicidad - la relación entre lo pasado y lo futuro-mediante interacciones simétricas entre actores del pasado y del porvenir. Por ejemplo, en los ritos del 8 de enero, cuando el ciclo anual de la fiesta Pascua Reyes pasa de manos de la Sociedad Sibimol a las de la Sociedad Agrícola o vice versa, integrantes uniformados de cada sociedad se manifiestan en actividades simétricas. En todos los casos mencionados aquí, la simetría se manifiesta mediante el intercambio de posiciones espaciales entre los grupos contrincantes, y por otras señales.

5. Por lo tanto, el intervalo ritual ofrece en su estructura de dualidades internas — sus turnos de juego- el espectáculo de una sociedad presente, una "ahora" en el mero acto de generar su futuro.

En Huarochirí dicen que la pichcamanta determina si será buen año o no. La frase es sugerente, porque el verbo determinar implica la misma ambigüedad que la pichcamanata expresa con recursos rituales. Determinar, según la Real Academia de la Lengua Española (DRAE, 1992, t. 1: 737) significa "distinguir, discernir", o sea descubrir lo ignoto. Pero a la vez significa "señalar, fijar una cosa para algún efecto", o sea decidir algo e imponer la voluntad humana.

En la sesión cívica de la Huayrona el futuro político se determina, vale decir, se decide, arrojando los mensajes verbales a través del espacio dicotomizado, cambiando lugares, y volviendo a arrojar.

En el juego y augurio, el futuro agroecológico se determina, vale decir, se descubre, arrojando troncos a través del espacio dicotomizado, cambiando lugares, y volviendo a arrojar.

En el componente político se acentúa la capacidad de agencia o actividad humana, y en el componente ritual, se acentúa lo que es imponderable para el ser humano, la indeterminación o, según ellos, la voluntad divina. Pero se homologan las dos arenas en un todo particular formal, de suerte que el ciclo sirve para homologar y fusionar las dos facetas de la condición humana como caras de una sola moneda. En ambos foros, la destreza de quien arroja influye en el futuro sin poder finalmente decidirlo. El devenir de la sociedad es efecto interactivo, entre la gente del pasado, los que produjeron los hechos conocidos, y la gente del futuro, los que lanzan los propósitos pensados, mediatizados por lo divino. El resultado del augurio se considera como el primer momento en el cual el perfil del cambio comienza a vislumbrarse. A la luz de ello, los socios comienzan a programar su año agropastoral. 
Es posible interpretar la "verdad" del augurio como profecía autoconfirmadora, porque si la gente dispone de sus recursos según las indicaciones de la pichcamanta, la mejor producción en efecto tomará lugar (ceteris paribus) donde los recursos se inviertan más. Igualmente es posible interpretar el rol del augurio con cierta frialdad política como mecanismo para encubrir o silenciar los conflictos entre diferentes cultivadores y pastores, que en realidad rivalizan ásperamente por recursos limitados de agua, de pastoreo y de tierras de arriendo. Sin duda la nota dominante en los discursos dedicatorios del augurio - el "actuar como un solo hombre" en la frase comúnmente repetidada - es la llamada a la solidaridad, cuya urgencia es de por sí elocuente. La fusión final de las voluntades en un regocijo ebrio y amorfo afirma lo mismo.

Pero no todo debe interpretarse como mistificación. En efecto, los participantes salen ganando cierta claridad de visión en cuanto a la nueva constelación política, y la vez maximizan sus habilidades para conducirla fraternalmente. No será pura coincidencia el hecho de que el Distrito de Tupicocha, notable por su intrincado ritualismo y su conservatismo cultural, fue reconocido en los festejos del Día del Campesino (Matucana, 22 de junio 2001) como "famoso por su sólido trabajo comunitario".

\section{Referencias citadas}

ADELAAR, W. F.H., 1994 - La procedencia dialectal del manuscrito de Huarochirí en base a sus características lingüísticas. Revista Andina, 12(1): 137-154.

AMSAT/SAT (Archivo de la Municipalidad de San Andrés de Tupicocha), 1903-1944 - Libro 6, Actas.

ARGUEDAS, J. M. \& DUVIOLS, P., 1966 - Dioses y hombres de Huarochirí, 278p.; Lima: Instituto de Estudios Peruanos.

ARRIAGA, P. J. de, 1968[1621] - Extirpación de la idolatría en el Perú. In: Crónicas peruanas de interés indígena (Francisco Esteve Barba, ed.): 191-277; Madrid: Ediciones Atlas. Biblioteca de Autores Españoles.

BELLEZA CASTRO, N., 1995 - Vocabulario jacaru-castellano, castellano-jacaru (aymara tupino), 306p.; Cuzco: Centro de Estudios Rurales Andinos "Bartolomé de las Casas".

BERTONIO, L., 1984[1613] - Vocabulario de la lengua aymara, LXXIV + $474+399$ p; Cochabamba: Centro de Estudios de Realidad Económica y Social (Xavier Albó \& Félix Laymi, eds.).

CARTER, W. \& MAMANI P., M., 1968 - Irpa Chico. Individuo y comunidad en la cultura aymara, IX + 460p.; La Paz: Librería-Editorial "Juventud".

COBO, B., 1964[1653] - Obras. Historia del Nuevo Mundo (2 tomos), 439 + 515p.; Madrid: Ediciones Atlas. Biblioteca de Autores Españoles 91, 92 (Francisco Mateos, ed.).

DRAE (Diccionario de la Real Academia Española), 1992 - T. 2, a-g. Madrid: Real Academia Española. Edición electrónica.

DUVIOLS, P., 1986 - Cultura andina y represión. Procesos y visitas de idolatría y hechicerías. Cajatambo, siglo XVII, LXXXVI + 568p.; Cuzco: Centro de Estudios Rurales Andinos "Bartolomé de las Casas".

GARCILASO DE LA VEGA, Inca, 1985[1609] - Comentarios reales de los Incas (2 tomos), 588p.; Caracas: Biblioteca Ayacucho.

GELLES, P., 1995 - Equilibrium and Extraction. American Ethnologist, 22(4): 710-742. 
GENTILE LAFAILLE, M., 1998 - La pichca: oráculo y juego de fortuna (su persistencia en el espacio y tiempo andinos). Bulletin de l'Institut Français d'Études Andines, 27(1): 75131; Lima.

GONÇÁLEZ HOLGUÍN, D., 1952[1608] - Vocabulario de la lengua general de todo el Peru llamada lengua qquichua o del Inca, XLIV + 707p.; Lima: Instituto de Historia [de la Universidad Nacional Mayor de San Marcos] (Raúl Porras Barrenechea, ed.).

GOSE, P., 1994 - Deathly Waters and Hungry Mountains: Agrarian Ritual and Class Formation in an Anddean Town, XVI + 325p.; Toronto: University of Toronto Press.

GUAMAN POMA DE AYALA, F., 1980[1613] - Nueva crónica y buen gobierno, XLVI + 1175p.; México: Siglo Veintiuno (John V. Murra, Rolena Adorno \& George L. Urioste, eds.).

HARRIS, O., 2000 - To Make the Earth Bear Fruit. Essays on Fertility, Work, and Gender in Highland Bolivia, IX + 251p.; London: Institute of Latin American Studies.

HARTMANN, R. \& OBEREM, U., 1968 - Beiträge zum "Huairu-Spiel”. Zeitschrift für Ethnologie 93(1/2): 240-259; Braunschweig.

JUAN, J. \& ULLOA de, A., 1978[1748] - Relación histórica del viaje a la América Meridional hecho por orden de Su Magestad para medir algunos grados de meridiano terrestre, 682p.; Madrid: Fundación Universitaria Española (JoséP. Merino Navarrro \& Miguel M. Rodríguez San Vicente, eds.).

KARSTEN, R., 1930a - Ceremonial Games of the South American Indians. Commentationes Humanarum Litterum, III: 2: 38p.; Societas Scientiarum Fennica, Helsingfors.

KARSTEN, R., 1930b - My Huairu Game Once More. Commentationes Humanarum Litterum, III: 7: 11p.; Societas Scientiarum Fennica, Helsingfors.

LABARRE, W., 1969[1948] - The Aymara Indians of the Lake Titicaca Plateau, Bolivia, 250p.; New York: Kraus Reprint. Memoir Series, American Anthropological Association, ${ }^{\circ}$ 68.

LIRA, J. A, 1982[1941]-Diccionario Kkechuwa-Español. 2da edición, 345p.; Bogotá: Secretaría Ejecutiva del Convenio "Andrés Bello". Cuadernos Culturales, $\mathrm{N}^{\circ} 5$.

MURÚA de, M., 1946[1590] - Historia del origen y genealogía real de los reyes incas del Perú. 444p.; Madrid: Consejo Superior de Investigaciones Científicas, Instituto Santo Toribio de Mogrovejo (Constantino Bayle, ed.)..

NIMUENDAJÚ, C., 1946 - The Eastern Timbira, X+261p.; Berkeley y Los Angeles: University of California Publications in American Archaeology and Ethnology, vol. 41.

NORDENSKIÖLD, E., 1930 - Huayru Game. Journal de la Société des Américanistes, 22: 211-213; Paris.

PAERREGAARD, K., 1987 - Death Rituals and Symbols in the Andes. Folk, 29: 23-42; Copenhagen.

PALOMINO FLORES, S., 1971 - La dualidad en la organización socio-cultural de algunos pueblos del área andina. Revista del Museo Nacional, 37: 231-260; Lima.

PLATT, T., 1986 - Mirrors and Maize. The Concept of yanantin Among the Macha of Bolivia. In: Anthropological History of Andean Polities (J.V. Murra, Nathan Wachtel \& Jacques Revel, eds.): 228-259; New York: Cambridge University Press.

POLIA MECONI, M., 1999 - La cosmovisión religiosa andina en los documentos inéditos del Archivo Romano dela Compañía de Jesús, 1581-1752,627p.; Lima: Pontificia Universidad Católica del Perú, Fondo Editorial.

RIVET, P., 1927 - Coutumes funéraires et jeux indiens. Journal de la Société des Américanistes n.s., XIX: 406-407; Paris.

ROCA WALLPARIMACHI, D., 1955 - Ceremonias de velorios fúnebres. Archivos Peruanos de Folklore, 1: 138-150; Cuzco. 
ROSTWOROWSKI, M., 1978 - El avance de los Yauyos hacia la costa en tiempos míticos. In: Señoríos indígenas de Lima y Canta: 31-44; Lima: Instituto de Estudios Peruanos.

SALOMON, F., 1997 - Los quipus y libros de la Tupicocha de hoy. In: Arqueología, antropología e historia en los Andes. Homenaje a Maria Rostworowski (Rafael Varón Gabai \& Javier Flores Espinoza, eds.): 241-258; Lima: Instituto de Estudios Peruanos.

SALOMON, F., 2002 - Patrimonial Khipus in a Modern Peruvian Village: An Introduction to the "Quipocamayos" of Tupicocha, Huarochirí. In: Narrative Records in the Inka Khipus: Memory, Mnemonics, and 'Writing' in the Andes (Gary Urton \& Jeffrey Quilter, eds.): 293-319; Austin: University of Texas Press.

TAYLOR, G., 1983 - Lengua general y lenguas particulares en la antigua provincia de Yauyos, Perú. Revista de Indias, 43 (171): 265-291.

TAYLOR, G., 1987 - Ritos y tradiciones de Huarochirí. Manuscrito quechua de comienzos del siglo XVII, 616p.; Lima: Instituto de Estudios Peruanos - Instituto Francés de Estudios Andinos. Versión paleográfica, interpretación fonológica y traducción al castellano. Estudio biográfico sobre Francisco de Avila por Antonio Acosta.

VALDERRAMA, R. \& ESCALANTE, C., 1980 - Apu Qorpuna: visión del mundo de los muertos en la comunidad de Awkimarca. Debates en Antropología, 5: 233-264; Lima. 